\title{
CONSUMOS MIDIÁTICOS, CONSUMIDORES EM DEBATE
}

O volume 11, número 1, da Signos do Consumo traz como eixo articulador entre os artigos aprovados a discussão dos consumos midiáticos e a concepção de consumidores aportadas por contextos comunicacionais. Esse conjunto de textos registra o fenômeno contemporâneo que permite compreender a comunicação a partir de seus consumos como marcas, produtos e serviços midiáticos ou não, mas trazendo no comum/comunicacional a perspectiva que encerra em si toda a finalidade da comunicação, a transformação dos sujeitos ou sua cooptação nos processos de apropriação, recepção e consumos.

$\mathrm{O}$ primeiro artigo, intitulado "O que pessoas comuns fazem à comunicação de marca? Uma análise de campanhas publicitárias francesas”, de Lorreine Beatrice Petters, da Universidade Sorbonne Nouvelle - Paris 3, traz a hipótese de que a representação de pessoas comuns na publicidade propicia maior identificação discursiva com os conteúdos de tais mensagens, por parte dos consumidores, ao se verem representados na lógica do imaginário das marcas. A autora, para esse propósito, analisou 140 mensagens francesas à luz das teorias discursivas.

O texto seguinte, "Soft Power e a construção simbólica da realidade: a influência da mídia no comportamento da sociedade - o caso da reforma da previdência no Brasil”, de Aryovaldo de Castro Azevedo Junior, da Universidade Federal do Paraná (UFPR), discute o tipo de influência e jogos de poder entre atores/agentes midiáticos na formação da opinião pública sobre as campanhas governamentais a favor da Reforma da Previdência Social no contexto brasileiro.

"Em nome do direito de ser criança: o papel vanguardista do marco legal da primeira infância no combate à pressão consumista e à comunicação mercadológica" é o artigo de Paulo Nassar, da Universidade de São Paulo (USP), e Ana Claudia Pompeu Torezan Andreucci, da Universidade Presbiteriana Mackenzie. O texto aborda, oportunamente, a importância do marco legal da Lei $n^{\circ} 13.257 / 2016$, que preserva a primeira infância da mira das estratégias capitalistas da comunicação mercadológica, trazendo à cena dos artigos em discussão o direito à preservação do consumidor infantil no período de zero a seis anos de idade.

Já a discussão do consumo midiático digital no universo religioso se faz representar no artigo "Religi@o 2.0: interações processuais e sistêmicas no blog do bispo Edir Macedo”, de Carlos Sanchotene, da Universidade Federal de Santa Maria (UFSM). O texto aponta para as lógicas comunicacionais dos usos e consumos midiáticos de fiéis à Igreja Universal do Reino de Deus, comandada pelo bispo Edir Macedo, em seu blog, discutindo a midiatização da fé na mediação tecnológica.

O quinto artigo, "A performance do comediante Whindersson Nunes: a imagem pública consumida como celebridade ordinária”, de Fabíola Carolina de Souza e Fernanda Faria Medeiros, ambas da Universidade Federal de Minas Gerais (UFMG), e Paulo Henrique Basílio Santana, da Pontifícia Universidade Católica de Minas Gerais (PUC-Minas), aborda as implicações do youtuber estudado na perspectiva dos conceitos de celebridade ordinária e performance, apontando para lógicas do seu sucesso no consumo midiático no Brasil.

A discussão sobre o ethos do leitor de editoriais de jornais como consumidor de conteúdos políticos via imprensa escrita está disponível 
no texto, intitulado "Basta e Basta: do ethos dos produtores à projeção dos sujeitos consumidores de editoriais em dois momentos distintos da política brasileira (1964 e 2016)”, de autoria de Tânia Hoff e Guy Pinto de Almeida Junior, ambos da Escola Superior de Propaganda e Marketing de São Paulo (ESPM-SP). Os autores realizam uma análise do discurso que apresenta aspectos semelhantes e específicos dos dois contextos históricos e jornalísticos selecionados para a comparação, mostrando como a impressa busca cooptar seus leitores a partir do imaginário ideológico que assume em seus editoriais.

O texto "Racismo brasileiro ou... quando o protagonista não é branco: a narrativa publicitária em 'Nesse dia dos Pais, dê O Boticário”, de Pablo Moreno Fernandes Viana e Dalila Maria Musa Belmiro, ambos da PUCMinas, é um ensaio que põe em discussão o negro representado na publicidade, especificamente a partir das repercussões sobre a campanha do Dia dos Pais (2018) da marca O Boticário, considerando a noção de família autocentrada que, na reflexão dos autores, faz emergir a lógica racista estrutural, presente na sociedade brasileira.

O oitavo artigo, intitulado "A apropriação do social pela publicidade: Skol Reposter e suas ideologias de consumo”, de Ana Paula Bragalia, da Universidade Federal Fluminense (UFF), aborda a responsabilidade social da marca Skol, diante da questão da representação do gênero feminino, como uma questão emocional da marca, constitutiva a sua ideologia de consumo em construção para com o público.

O último texto desta edição faz uma reflexão ensaística sobre o audiovisual (videoclipe) “Corpo fechado”, de Johnny Hooker, lançado em 2018, para pensar o cruzamento das questões de negociação de outras masculinidades diante do hegemônico e suas possibilidades no contexto contemporâneo do consumo midiático como consumo político, que pode favorecer a assimilação da diversidade de gênero. Assim, "Diversidade, gênero e consumo: estudos contemporâneos”, de Wilton Garcia, da Universidade de Sorocaba (Uniso), encerra este número da Signos do Consumo trazendo a questão do produto audiovisual e seu consumo para além da mercadoria, e como ação política de outras negociações na vida social sobre a diversidade de gênero.

Por fim, apresenta-se a resenha intitulada "O panorama dos estudos de recepção e consumo midiático no Brasil: contribuições do estado da arte em Meios e Audiências III", realizada por Guilherme Libardi, da Universidade Federal do Rio Grande do Sul (UFRGS), que nos oferece uma leitura sobre a terceira publicação referente às relações entre meios e audiências, a partir do trabalho coordenado pelas professoras Nilda Jacks, Elisa Pedras, Mônica Pieniz e Valquíria John na Universidade Federal do Rio Grande do Sul (UFRGS) e na UFPR.

Diante do conjunto de textos aqui reportados, deixamos como comentários finais os nossos agradecimentos aos pareceristas deste número, cuja contribuição oferece qualidade aos processos editorias da Signos do Consumo, e desejamos a todos uma ótima leitura! 